\title{
The automation hardware control and management of industrial processes
}

\section{Nikolaev Andrey Borisovich}

Russian Federation, Honoris Causa, Doctor of Technical Sciences, Professor, Dean of the Faculty «Control Systems».

Moscow Automobile \& Road construction State Technical University, 125319, Russian Federation, Moscow, Leningradsky prospekt, 64. Tel.: +7 (499) 151-64-12. http://www.madi.ru

nikolaev.madi@mail.ru

\section{Vasiuhova Svetlana Alekseevna}

Russian Federation, Postgraduate Student, Department of «Automated Control Systems».

Moscow Automobile \& Road construction State Technical University, 125319, Russian Federation, Moscow, Leningradsky prospekt, 64. Tel.: + 7 (499) 151-64-12. http://www.madi.ru

\section{vas715@gmail.com}

\begin{abstract}
This article analyzes the problems of automation of industrial processes, as well as the problem of the use of technical means to establish and maintain these processes. Under Article analysis of existing software and hardware systems and external equipment. The article describes the basic structure of software and hardware systems, consisting of several levels.

During the analysis of an experiment to evaluate the quality of the color sensor in the same conditions outside the working space. The experiment consists of two stages. The experiment was to determine the color and color sorting items. Sort carried out to develop a model of an industrial robot - sorter based designer LEGO. The first phase was conducted with an uncalibrated sensor, and the second phase was conducted after calibration color sensor. The findings showed that the calibration and testing of the external equipment are necessary for quality and proper operation of the PTC and robotic devices.
\end{abstract}

Keywords: automation, controller, PTC, software and hardware, LEGO NXT, sensor, sorting, server. 
ISSN 2306-1561

Автоматизация и управление в технических системах (АУТС) 2014. - №1.1(8). - C. 129-139.

DOI: $10.12731 / 2306-1561-2014-1-14$

УДК 681.518

\section{Технические средства автоматизации по контролю и управлению промышленными процессами}

\section{Николаев Андрей Борисович}

Российская Федерация, Лауреат премии правительства РФ, Заслуженный деятель науки РФ, доктор технических наук, профессор, декан факультета «Управление».

ФГБОУ ВПО «Московский автомобильно-дорожный государственный технический университет (МАДИ)», 125319, Российская Федерация, г. Москва, Ленинградский проспект, д.64, Тел.: +7 (499) 151-64-12, http://www.madi.ru

nikolaev.madi@mail.ru

\section{Васюгова Светлана Алексеевна}

Российская Федерация, аспирант кафедры «Автоматизированные системы управления».

ФГБОУ ВПО «Московский автомобильно-дорожный государственный технический университет (МАДИ)», 125319, Российская Федерация, г. Москва, Ленинградский проспект, д.64, Тел.: +7 (499) 151-64-12, http://www.madi.ru

vas715@gmail.com

Аннотация. В статье анализируются проблемы автоматизации промышленных процессов, а также, проблемы использования технических средств, обеспечивающих и поддерживающих данные процессы. В рамках статьи проведен анализ существующих программно-технических комплексов и внешнего оборудования. В статье приводятся основные структуры программно-технических комплексов, состоящие из нескольких уровней.

В ходе анализа поставлен эксперимент по оценке качества работы датчика цвета в одинаковых условиях внешнего рабочего пространства. Эксперимент состоит из двух этапов. Суть эксперимента заключалась в определении цвета и сортировке цветных предметов. Сортировка осуществлялась разработанной моделью промышленного робота-сортировщика на базе конструктора LEGO. Первый этап проводился с неоткалиброванным датчиком, а второй этап проводился после калибровки датчика цвета. Полученные данные показали, что калибровка и тестирование внешнего оборудования являются необходимыми для качественной и правильной работы ПТК и роботизированных устройств. 
Ключевые слова: автоматизация, контроллер, ПТК, программно-технический комплекс, LEGO NXT, датчик, сортировка, сервер.

\section{1. Введение}

В настоящее время автоматизация большинства технологических процессов происходит на основе универсальных микропроцессорных контроллерных устройств. Данные устройства получили название программно- технических комплексов (ПТК).

Данные комплексы являются совокупностью микропроцессорных средств автоматизации, контроллеров, серверов различного назначения, программного обеспечения контроллеров и дополнительного оборудования, а также, промышленных сетей, которые позволяют организовать связь между перечисленными элементами. Стоит отметить, что ПТК для одного предприятия может кардинально отличаться от ПТК, внедренного на другое предприятие. В основном это обусловлено классификацией оборудования, которое эксплуатируется на предприятии.

Программно- технические средства чаще всего предназначены для разработки распределительных систем управления технологическими процессами. Данные процессы могут иметь различную информационную мощность, т.е. количества входных/выходных сигналов.

Для того чтобы организовать соединение всех устройств и элементов комплекса, используются принципы унификации, типизации и агрегатирования [1, 11, 21 - 28].

Также, очень важным вопросом является проблема создания эффективных систем физической защиты различного рода объектов. Выполнение системой безопасности своих целевых функций напрямую зависит от своевременности и достоверности факта обнаружения ею нарушителя, т.е. от эффективности организации системы обнаружения, в частности выбора технических средств обнаружения (ТCO) для конкретного объекта защиты с учетом его специфических особенностей и их дальнейшего размещения на объекте [5 - 10].

\section{2. Классификация программно- технических комплексов}

Сегодня существует большой выбор программно- технических комплексов, которые имеют свою классификацию [2, 9, 24 - 26]. Выбор того или иного микропроцессорного ПТК зависит от требований и нужд предприятия. Каждый класс таких комплексов предназначен выполнять определенный набор задач и определенный объем получаемой и обрабатываемой информации.

Классификация ПТК:

- контроллер на базе персонального компьютера (PC);

- локальный программируемый контроллер (PLC), который может быть двух типов: встраиваемый и автономный;

- сетевой комплекс контроллеров (PLC, NETWORK);

- распределенные маломасштабные системы управления (DCS, SMOLLER SCALE); 
- полномасштабные распределенные системы управления (DCS, FULL SCALE).

Bce вышеперечисленные типы ПТК имеют различные области применения и характеристики. Например, ПТК на базе персонального компьютера применяются для управления небольшими замкнутыми объектами в промышленности, в медицине, в научных лабораториях и в других специализированных системах автоматизации. А функции реализации программируются не на специализированном языке программирования, а на обычном языке программирования высокого уровня (C++, РНP и др.).

Сегодня чаще всего применяются ПТК, включающие в себя контроллеры с локальным типом управления и программирования. Локальный программируемый контроллер отличается от обычного возможностью дистанционного изменения условий и задач работы системы. Такие контроллеры имеют порты для соединения в режиме «точка-точка» с другими устройствами, компьютерами, модулями, датчиками и интерфейсами. Чаще всего контроллеры имеют от нескольких до десятков и сотен входов/выходов.

\section{3. Функциональная схема и задачи контроллера}

Контроллеры осуществляют простые операции по обработке измерительной информации, регулирования и программно-логического управления процессами, блокировка, подача сигналов и информации оператору.

Функциональная схема контроллера [3] представлена на рисунке 1.

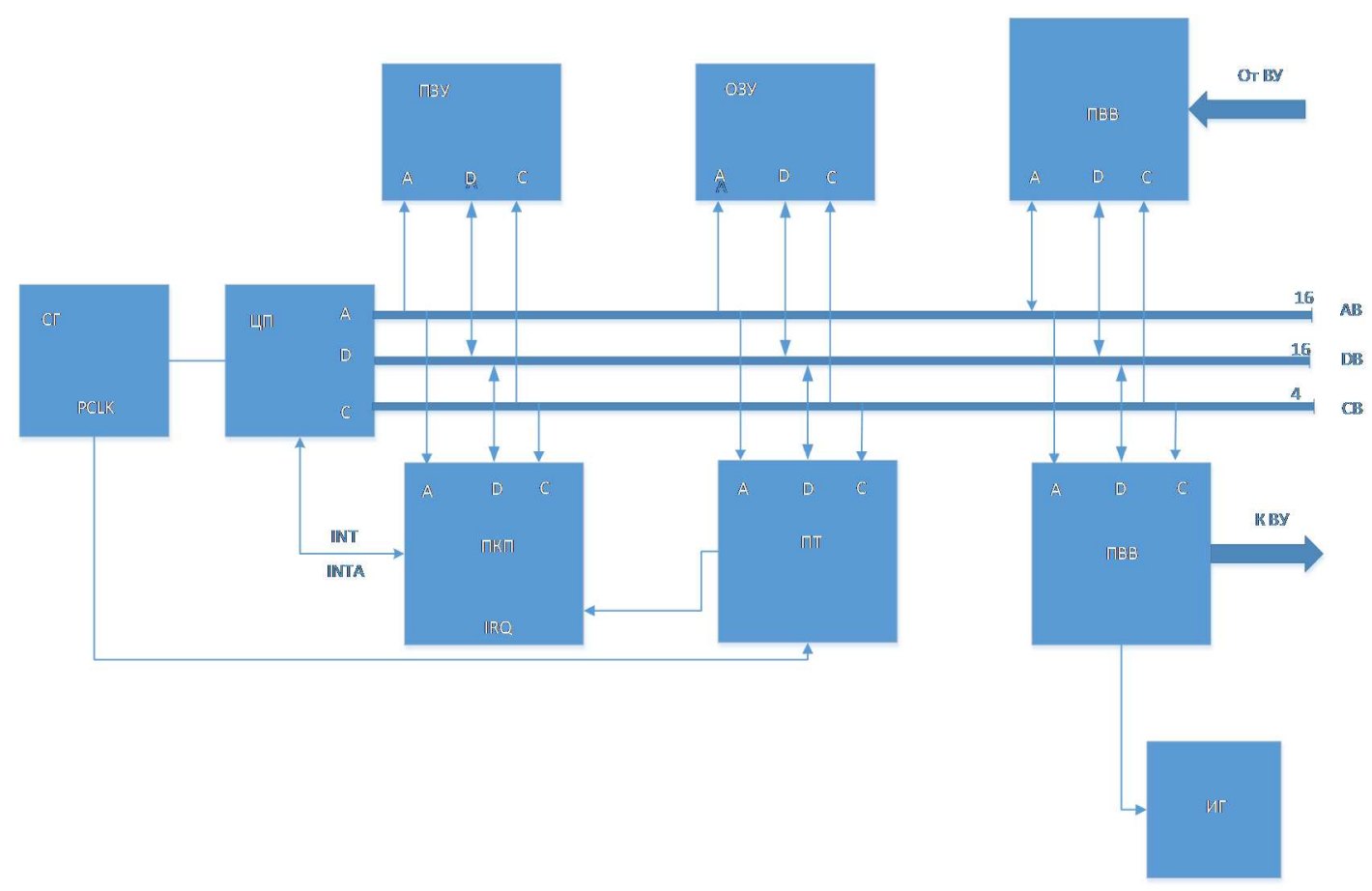

\section{Рисунок 1- Функциональная схема контроллера}

При наличии встроенных модулей дистанционной связи управление процессами контроллера и получение выходных данных может осуществляться на расстоянии, что 
позволит увеличить производительность и снизить время, затрачиваемое на получение, обработку и корректировку информации.

На рисунке 1 изображена общая функциональная схема контроллера. Контроллер состоит из комплекса взаимодействующих блоков.

Элементы, входящие в схему:

- СГ - системный генератор;

- ЦП - центральный процессор;

- ПЗУ - постоянное запоминающее устройство;

- ОЗУ - оперативное запоминающее устройство;

- ПК - программируемый контроллер прерываний;

- ПТ - программируемый таймер;

- ИГ - индикатор готовности;

-

На рисунке видно, что информация подается от внешнего устройства (ВУ), после чего она обрабатывается контроллером и подается обратно на внешнее устройство. Индикатор готовности информирует о нормальной работе устройства - в случае возникновения ошибок индикатор гасится.

Системная шина контроллера состоит из трех составляющих: шины адреса (AB), шины данных (DB), шины управления (CB).

\section{4. Структура программно- технического комплекса}

При групповом использовании комплексов различного назначения возникает ряд весьма сложных задач, в первую очередь, связанных с проблемой управления ими и организацией взаимодействия между элементами системы [6]. Структура ПТК может различаться между собой, однако, можно выделить основные функциональные элементы таких комплексов:

- программируемые контроллеры;

- интеллектуальные средства связи с объектом;

- промышленные сети;

- серверы;

- прикладное программное обеспечение.

Также, программно-технические комплексы включают в себя многочисленные внешние или встроенные устройства анализа и измерения условий окружающей среды (датчики, сенсоры и т. д.).

Сама структура ПТК зависит от характеристик и условий взаимосвязи между функциональными элементами комплекса, скорости передачи и обработки информации, типа функционального элемента комплекса, удаленности устройств друг от друга, количества узлов и других элементов.

На рисунке 2 представлена наиболее общая и простая структура ПТК [4]. Функционирование данной системы, как видно на рисунке 2 , происходит на двух 
уровнях. Первый уровень содержит контроллеры, а второй уровень включает в себя пульт оператора.

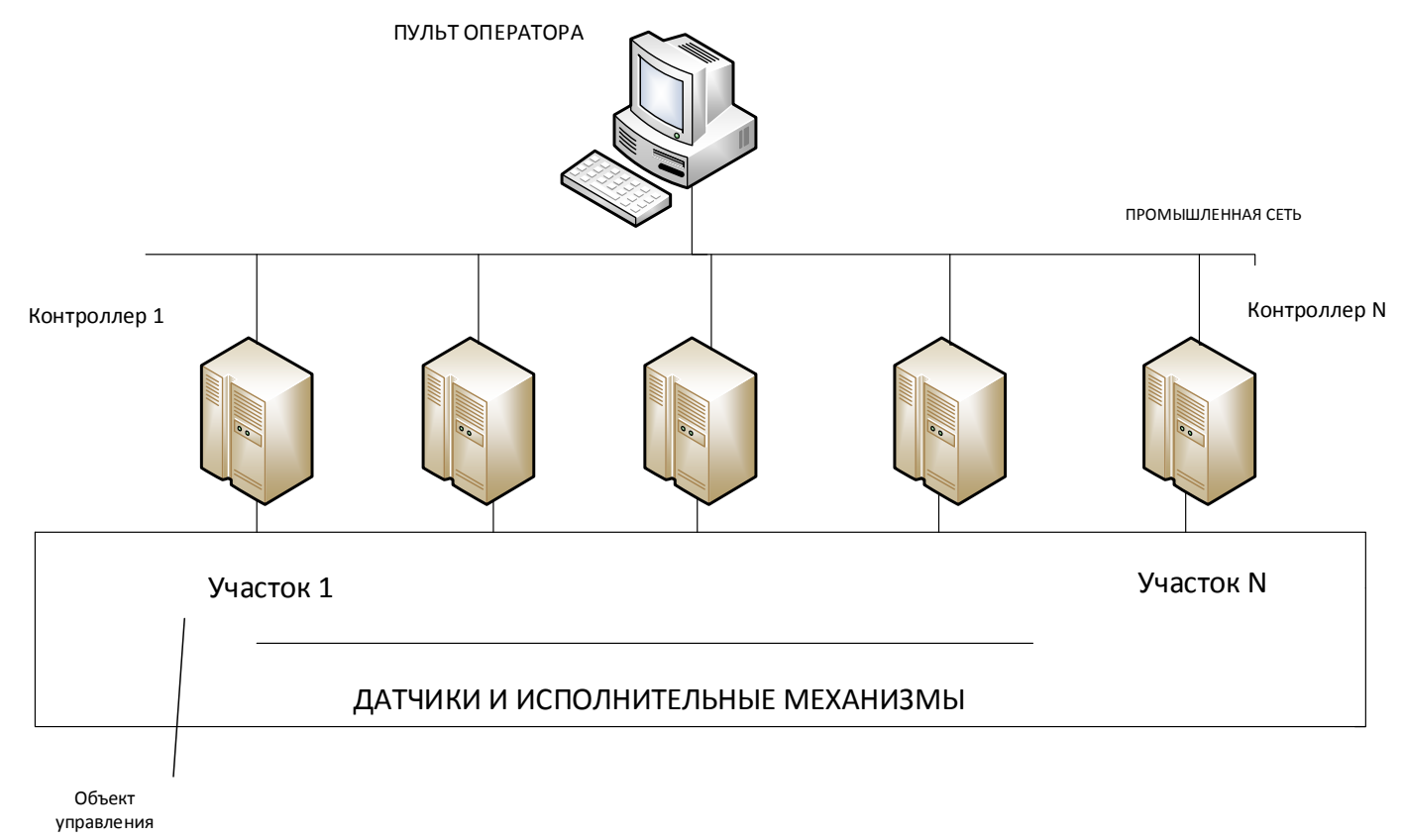

Рисунок 2 - Структура ПТК

Пульт оператора представляет собой центральный компьютер или внутреннюю рабочую станцию. Данный уровень формирует запросы к уровню контроллеров и получает необходимую информацию. Полученная информация представлена в удобном для пользователя виде. Также, устройство первого уровня осуществляет запись и хранение полученной информации.

Уровень контроллеров отвечает за сбор сигналов, получаемых от датчиков и сенсоров; обработку полученной информации (фильтрацию, масштабирование и т. д) при помощи встроенных алгоритмов управления; формирование управляющих сигналов; прием и передача информации, полученной от промышленной сети.

Однако с увеличением объема задач, информационной и производительной мощности, совершенствованию технических устройств появляется потребность в разработке и внедрении более масштабных программно- технических комплексов.

В таких случаях (и чаще всего) функционирование программно-технических комплексов происходит на основе архитектуры «клиент-сервер». Серверы разрабатываются, как правило, на основе промышленных компьютеров и являются резервуарными.

Сервер выполняет следующие функции:

- сбор и обработка данных, полученных от контроллеров и функциональных устройств;

- хранение полученной информации;

- отображение полученной и сохраненной информации;

- подача управляющих команд контроллерам; 
- предоставление необходимой информации клиентским рабочим станциям;

- архивация отчетов, статистики, истории событий, документов и протоколов.

Структура программно-технического комплекса с архитектурой «клиент-сервер» продемонстрирована на рисунке 3 [4].

Современные ПТК включают в себя дополнительные модули и блоки, как встроенные, так и внешние. Они позволяют ПТК собирать информацию об окружающей среде, контролировать внешние процессы, обеспечивать удобный доступ к рабочим объектам, безопасность и возможность организации рабочего пространства с прямым и быстрым доступом до всех элементов комплекса. Под этими модулями и блоками подразумеваются различные датчики, сенсоры, камеры, барьерные щиты, монорельсы и мосты для расположения манипуляторов и других роботизированных устройств, и многое другое оборудование.

Открываются широкие возможности в применении оборудования, оснащенного цифровым программным управлением (ЦПУ), для решения задач автоматизации мелкосерийного и серийного производства. Если на первых порах роботы заменяли человека на утомительных и опасных работах, то в дальнейшем сфера их применения охватила и производственные операции, например, организация и контроль автоматизированной промышленной деятельности, покраска, сварка, подача исходных материалов и снятие готовой продукции.

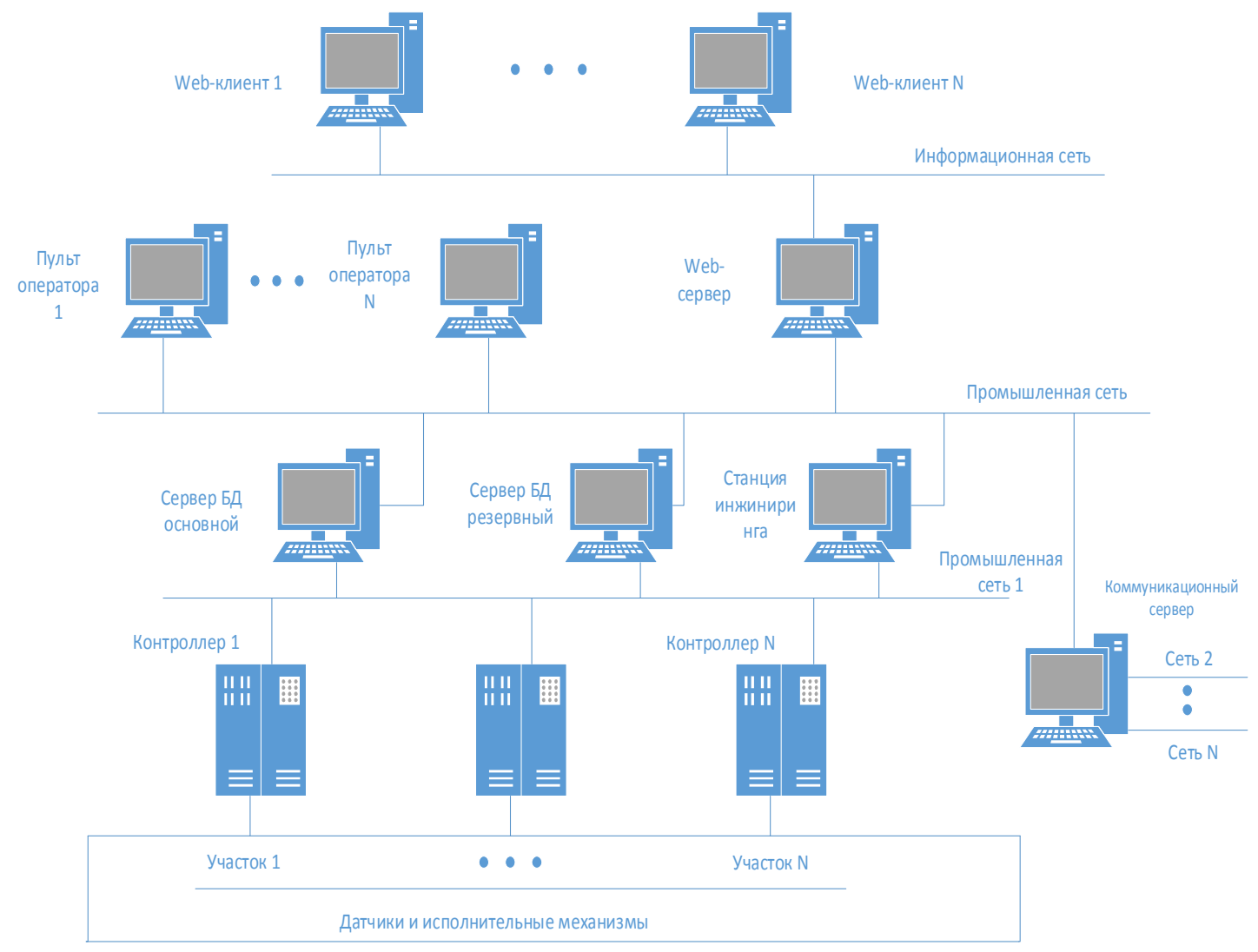

Рисунок 3- Структура ПТК с архитектурой «клиент-сервер» 
Использование промышленной сети позволяет разместить рабочие узлы, под которыми подразумеваются контроллеры и логические устройства «ввода-вывода», максимально близко по отношению к внешним модулям и устройствам.

\section{5. Тестирование датчика цвета на базе разработанной модели промышленного робота-сортировщика}

Программно-технические комплексы часто включают в себя различные внешние модули и устройства. Это необходимо для расширения объема задач и увеличения областей применения таких комплексов. Почти все роботизированные системы и ПТК имеют встроенные или внешние датчики и сенсоры, камеры и модули дистанционной связи. Благодаря подобным модулям, оборудованный комплекс или система способны собирать информацию об окружающем пространстве, реагировать на изменения в рабочей среде, а также, дистанционно получать и отправлять информацию.

Однако существует ряд проблем, связанный с эксплуатацией таких элементов. Основная проблема заключается в сверхчувствительности датчиков, сенсоров и камер. Любые незначительные изменения условий рабочей среды могут повлиять на работу данных устройств. В связи с этим необходимо обеспечить постоянные условия рабочей среды [12 - 20, 24 - 28]. Если ПТК или роботизированная система используются в условиях, подразумевающих постоянные изменения условий рабочего пространства и рабочей среды, то необходимо использовать внешние устройства, приспособленные к подобным условиям. Также, необходимо проводить регулярное тестирование и калибровку оборудования. Чтобы доказать необходимость постоянной проверки оборудования и ее калибровки, был проведен эксперимент.

В рамках исследования был поставлен эксперимент по тестированию работы датчика цвета, установленного как дополнительное внешнее оборудование в разработанную модель промышленного робота-сортировщика. Данный эксперимент поставлен в целях наблюдения и анализа качества работы датчика цвета. Робот создан на базе конструктора LEGO с контроллером NXT. Датчик цвета отличает шесть цветов или раскладывает принятый цвет на три цвета режима RGB (красный, зеленый, синий); фиксирует внешнее освещение в условных единицах; фиксирует отраженный свет, созданный собственным излучателем, и выдает результат в условных единицах на контроллер.

Эксперимент проводился в условиях с постоянным освещением. Суть эксперимента заключается в сортировки предметов по цвету (красный и синий). Эксперимент состоит из двух этапов. Первый этап сортировки проводится не откалиброванным датчиком. Второй этап сортировки будет выполняться после калибровки датчика. Каждый этап содержит 10 тестов. 
Результаты первого этапа эксперимента приведены в таблице 1.

Таблица 1- Данные первого этапа эксперимента

\begin{tabular}{|l|c|c|c|c|c|c|c|c|c|c|}
\hline Цвет & 1 & 2 & 3 & 4 & 5 & 6 & 7 & 8 & 9 & 10 \\
\hline Красный & + & + & + & + & - & - & + & + & - & - \\
\hline Синий & + & + & + & - & - & - & - & - & - & + \\
\hline
\end{tabular}

Результаты второго этапа эксперимента приведены в таблице 2.

Таблица 2- Данные второго этапа эксперимента

\begin{tabular}{|l|c|c|c|c|c|c|c|c|c|c|}
\hline Цвет & 1 & 2 & 3 & 4 & 5 & 6 & 7 & 8 & 9 & 10 \\
\hline Красный & + & + & + & + & + & + & + & + & - & + \\
\hline Синий & + & + & + & + & + & + & - & + & + & + \\
\hline
\end{tabular}

Как видно из результатов эксперимента, калибровка значительно повлияла на качество работы датчика цвета. Количество ошибок на втором этапе эксперимента уменьшилось почти втрое. Это говорит о том, что калибровка и тестирование оборудования является необходимым для выполнения качественной и правильной работы всей системы.

\section{6. Заключение}

В настоящее время автоматизация большинства технологических процессов происходит на основе универсальных микропроцессорных контроллерных устройств. Данные устройства получили название программно- технических комплексов (ПТК).

В статье проведен анализ существующих программно-технических комплексов и внешнего оборудования. Поставлен эксперимент по оценке работы датчика цвета. Полученные данные показали, что калибровка и тестирование внешнего оборудования являются необходимыми для качественной и правильной работы ПТК и роботизированных устройств.

\section{Список информационных источников}

[1] Родионов В.Д., Терехов В.А., Яковлев В.Б. Технические средства АСУ ТП. Под. ред. В.Б. Яковлева. М.: Высшая школа, 1989. 263 С.

[2] Ицкович Э.Л. Классификация микропроцессорных программно-технических комплексов// Промышленные АСУ и контроллеры. 1999. №10.

[3] Веб-сайт:http://www.km.ru/referats/9181B70DC4934DBA83D01272B7DF150E\#

[4] И.А. Елизаров, Ю.Ф. Мартемьянов, А.Г. Схиртладзе, С.В. Фролов. Технические средства автоматизации// Программно-технические комплексы и контроллеры. М.: Изд. Машиностроение-1. 2004.

[5] Н. В. Давидюк. Автоматизация процедуры подбора технических средств обнаружения системы физической защиты объектов// Вестник АГТУ. Сер. Управление, вычислительная техника и информатика. 2009. № 1. С. 1-3. 
[6] Каляев И. А., Капустян С. Г., Гайдук А. Р// Управление большими системами: сборник трудов. 2010. № 30-1. С. 606-608.

[7] Каляев И А., Лохин В.М., Макаров И М. и др. Интеллектуальные роботы / Под общей ред. Е.И. Юревича. - М.: Машиностроение, 2007. - 360 с.

[8] Каляев И.А., Гайдук А.Р., Капустян С.Г. Методы и модели коллективного управления в группах роботов. - М.: ФИЗМАТЛИТ, 2009. - 280 с.

[9] Ицкович Э.Л. Методы рациональной автоматизации производства. 2009. С. 11-20.

[10] Красовский А.А., Наумов А.И. Аналитическая теория самоорганизующихся систем управления с высоким уровнем искусственного интеллекта // Известия РАН. Теория и системы управления. - 2001 - №6. - С. 69-75.

[11] Александров А.Г. Оптимальные и адаптивные системы. - М.: Высшая школа, 1976. - $262 \mathrm{c}$.

[12] Лункин Б.В. Диагностирование датчиков на объектах контроля и управления // Автоматика и телемеханика. — 2003. — № 11. — С. 183-194.

[13] Лункин Б.В. Основы теории чувствительных элементов слоистой структуры радиоволновых датчиков // Тр. ИПУ. - М., 2002. - Т. XVI. - С. 7-20.

[14] Полярус А. В., Поляков Е. А., Марущенко Ю. В. Требования к точности измерения сигналов на выходе датчиков для обеспечения качественного восстановления входного сигнала// Вестник Харьковского национального автомобильно- дорожного университета. 2011. № 53.

[15] Трахтенгерц Э. А. Компьютерные технологии коррекции целей, стратегических решений и оперативных воздействий в динамике управления// Управление большими системами, Выпуск 23.

[16] Фролова М. В., Цыпин Б. В. Система удаленного конфигурирования интеллектуальных датчиков//Труды международного симпозиума "Надежность и качество". 2010. Том 1.

[17] Родионов В. Д. Технические средства АСУ ТП: учебное пособие / В. Д. Родионов, В. А. Терехов, В. Б. Яковлев. - М.: Высшая школа, 1989. — 263 с. : ил. — ISBN 5-06-000132-6.

[18] Г.Олссон, Д.Пиани. Цифровые системы автоматизации и управления. - СПб.: Невский Диалект, 2001. - 557 с.

[19] Меньков, Александр Викторович. Теоретические основы автоматизированного управления: учебник / А. В. Меньков, В. А. Острейковский. - М.: Оникс, 2005. - 640 с.: ил. - Список литературы: с. 609-610. — ISBN 5-488-00129-8.

[20] Фройден Дж. Современные датчики. Справочник / Перев. С англ. - М.: Техносфера, 2006. - 592 с.

[21] Васюгова С.А. Исследование перспектив и проблем интеграции человека с компьютером: искусственный интеллект, робототехника, технологическая сингулярность и виртуальная реальность / А.В. Остроух, С.А. Васюгова, М.Н. Краснянский, А. Самаратунга // Перспективы науки. - 2011. - № 4(19). - С. 109 112.

[22] Васюгова С.А. Моделирование поведения интеллектуального робота / С.А. Васюгова, Чаудхари Раджа Рам, О.И Максимычев, А.М. Васьковский // В мире научных открытий. - 2012. - №2.6 (26). - С. 110 - 114.

[23] Васюгова С.А. Анализ процессов моделирования и программирования промышленных роботов // Автоматизация и управление в технических системах. - 2013. - № 4.1. - C. 7-17. DOI: 10.12731/2306-1561-2013-4-3.

[24] Остроух А.В. Основы построения систем искусственного интеллекта для промышленных и строительных предприятий: монография / А.В. Остроух. - М.: OОО «Техполиграфцентр», 2008. - 280 с. - ISBN 978-5-94385-033-2. 
[25] Остроух А.В. Информационные технологии в научной и производственной деятельности / [ред. А.В. Остроух] - М: ООО "Техполиграфцентр", 2011. - 240 с. ISBN 978-5-94385-056-1.

[26] Остроух А.В. Ввод и обработка цифровой информации: учебник для нач. проф. образования / А.В. Остроух. - М.: Издательский центр «Академия», 2012. - 288 с. - ISBN 978-5-7695-9457-1.

[27] Остроух А.В. Системы искусственного интеллекта в промышленности, робототехнике и транспортном комплексе: монография / A.B. Остроух Красноярск: Научно-инновационный центр, 2013. - 326 с. - ISBN 978-5-906314$10-9$.

[28] Остроух А.В., Тянь Юань. Современные методы и подходы к построению систем управления производственно-технологической деятельностью промышленных предприятий // Автоматизация и управление в технических системах. - 2013. - № 1(3). - C. 29-31. 